\title{
Identification of Software NFR based on the Fuzzy-QFD Model
}

\author{
Shucheng Xiao*, Jiafeng Wu, Erhua He and Zhendong Yang \\ Chongqing Logistical Engineering University, China \\ xiaosc@cqu.edu.cn
}

\begin{abstract}
NFR determination of the software products is an important link in the requirement development. Considering the correlation and inter-dependence between FR and NFR of software, this paper puts forward a NFR system identification method of the software products based on the fuzzy-QFD model through constructing the FR-NFR correlation matrix of software. The model express correlation evaluation with the 7-level natural language, build the software FR-NFR correlation matrix, fuzzy the matrix vector by the trapezoidal fuzzy number, then calculate the relative importance and absolute importance of NFR, at last get the importance NFR by the NFR screening algorithm.
\end{abstract}

Keywords: software requirement; NFR; QFD; trapezoidal fuzzy number

\section{Introduction}

Functional requirement (FR) and non-functional requirement (NFR) are two core parts of software requirement. FR defines the functions that the software product must implement. Users use those functions to accomplish the specific tasks and business requirements. NFR is the quality description of the software product, including the constraints of software quality in different aspects, so as to ensure reliable operation of the software product as expected. In fact, software NFR decides the architecture design of development [1] which FR should also abide. Thus, clarifying the NFR of a software product is the problem of primary importance in the software requirement development as well as the basis for ensuring its reliability in the later stage.

The existing studies on software requirement mostly focus on FR acquisition and recognition, such as domain-based model [2], ontology description [3], manual [4], opinion [5], scene [6-7], requirement identification [8-11], ethnography-based cognition engineering and other methods [12-13], but little has been carried out on NFR. In addition, the existing studies are mainly based on the influence of NFR on software architecture design [14], definition of NFR classification [15-20] and evaluation of NFR importance [21-25]. Identifying NFR of the software product accurately is an important link in the requirement development [26]. QFD can overcome some problems appearing in the requirement analysis [27], effectively recognize users' requirements, convert them into a series of detailed design specifications, and identify the relative importance of different NFR attributes of the software product [28-29]. Moreover, the effectiveness of QFD in the software requirement development has been recognized [30-33], so the research is also based on QFD model.

Considering the correlation and interdependence between FR and NFR, this paper puts forwards a NFR determination method containing six steps through constructing the fuzzy-QFD model based on the FR-NFR correlation matrix of the software product. Chapter 1 summarizes the possible software NFRs according to the existing literature. Chapter 2 introduces the software NFR determination process based on the fuzzy QFD in details. ${ }^{1}$

*Shucheng Xiao is the corresponding author. 


\section{Software NFR Determination Process Based on the Fuzzy-QFD Model}

The NFR determination method based on the fuzzy-QFD model proposed in the paper is shown in Figure 1.

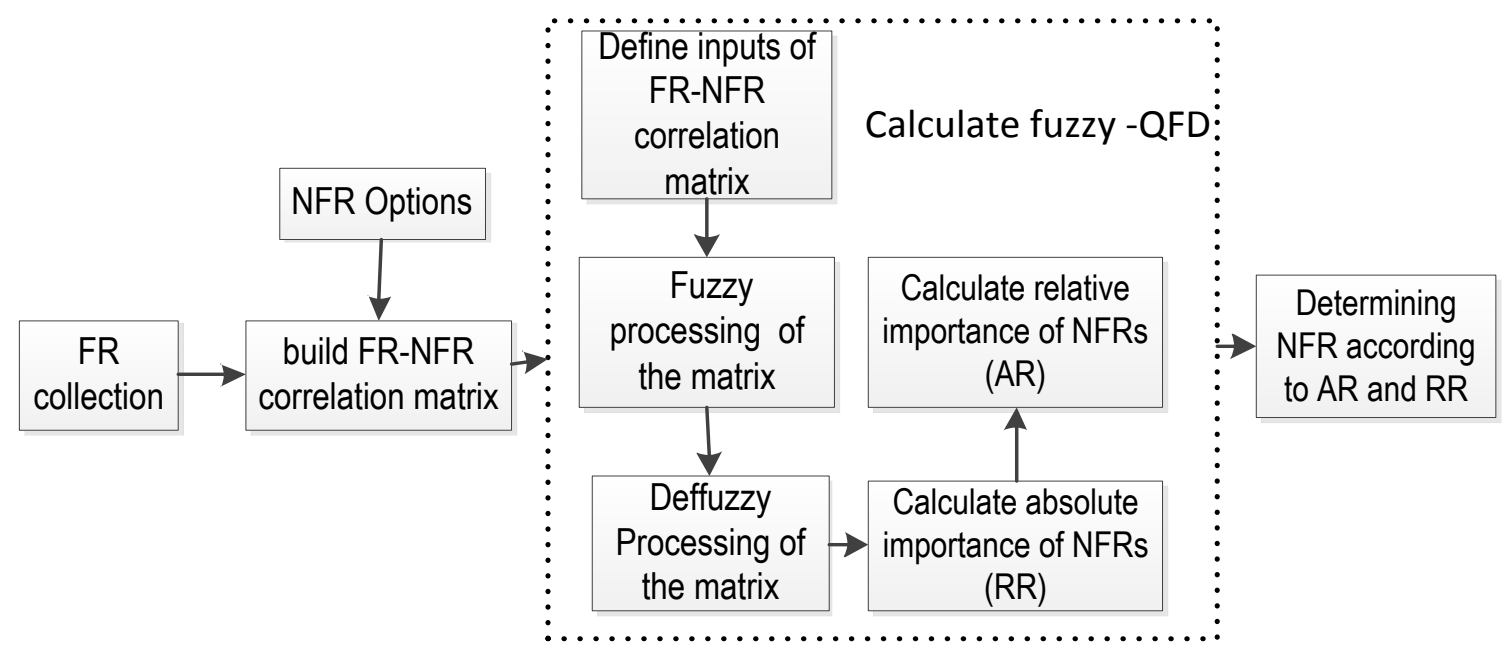

Figure 1. NFR Determination Method based on the Fuzzy-QFD Model

\subsection{FR Collection}

FR is the definition and specification of what the software system needs to do. It is the carrier of NFR. Thus, FR collection of the software product is the first step. At present, software FRs can be collected by the BPR process, GORA method, in-depth interview and requirement analysis of the original system. They are reflected by some basic user requirements and standards and functions, scenes or cases related to the business process and expressed in the set form after screening, decomposition, weighing and confirmation $\{\mathrm{FR} 1, \mathrm{FR} 2, \ldots, \mathrm{FRn}\}$.

\subsection{Optional NFR}

ISO/IEC 25010, which supersedes ISO/IEC 9126-1, was issued in March 2011. It has eight product quality characteristics (NFRs) and 31 sub-characteristics, but above NFRs focus only on the quality characteristics of software. For the information system development of an enterprise, however, many technical factors like architecture type, interface standard and version assessment and social and economic factors like legal permission, organization strategy, market orientation, technical training and support, reputation and ability of the developer should also be taken into account. Therefore, the domestic and foreign scholars [14-20] have added some other NFRs later.

This paper generalizes NFRs mentioned in above literature and proposes the NFR layered model as shown in Figure.2. NFRs in the model are reflected in three aspects: quality property, technical factor and socio-economic factor. Those three aspects are further subdivided into different primary and secondary sub-attributes. According to the definition of IEEE software engineering ISO/IEC 25010-2011, NFR is used to describe how a software system is designed to meet users' requirements. 43 sub-attributes in the 
NFR layered model can reflect the implementation of a software system from different perspectives. Thus, this paper regards those 43 candidate NFRs of the software system as the column of the FR-NFR correlation matrix.

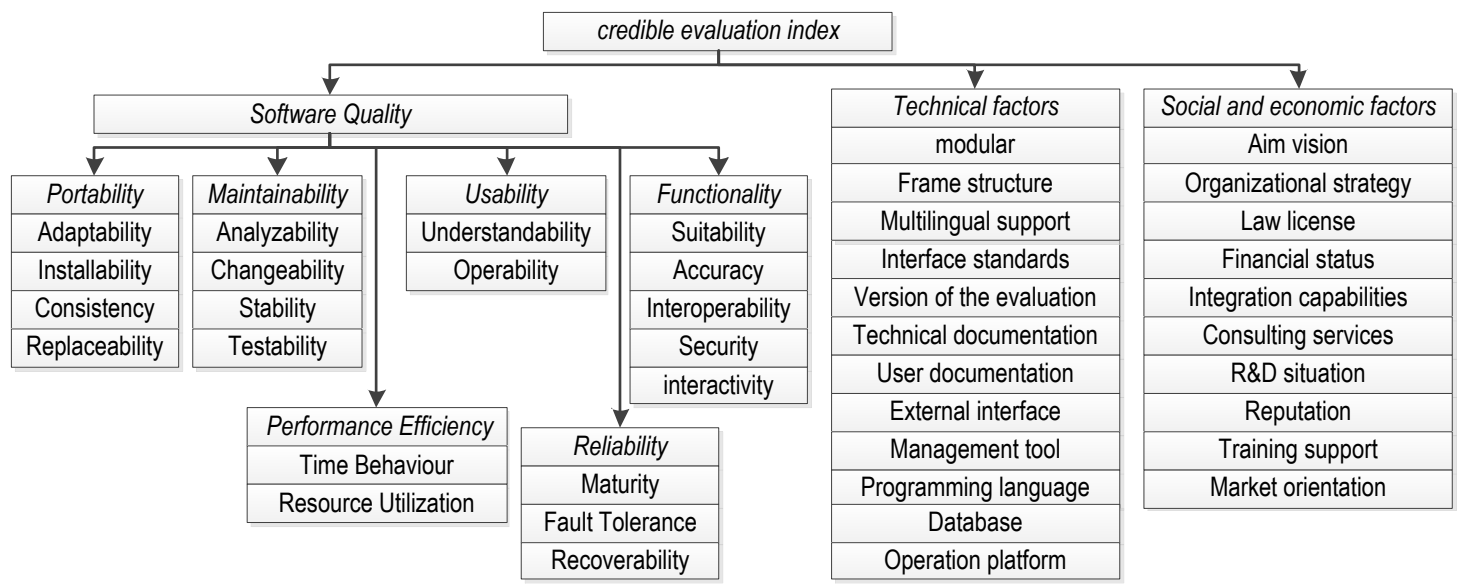

Figure 2. Credible Evaluation Index

\subsection{FR-NFR Correlation Matrix}

It is assumed that $F R_{n}$ is FR of No. $n$ and $\left\{F R_{1}, F R_{2}, \ldots, F R_{n}\right\}$ is the FR set of the software. For each $F R_{i}$, relevant participants need to give the correlation evaluation between $F R_{i}$ and 44 NFRs $\left\{N F R_{1}, N F R_{2}, \ldots, N F R_{44}\right\}$ above which is described by the 7-level natural language variable (very strong, strong, a little strong, ordinary, a little weak, weak and very weak). The results constitute the FR-NFR correlation matrix, as shown in Table 1.

Table 1. The FR-NFR Correlation Matrix

\begin{tabular}{c|cccc} 
& $N F R_{1}$ & $N F R_{2}$ & $\cdots$ & $N F R_{44}$ \\
\hline$F R_{1}$ & $R_{11}$ & $R_{12}$ & $\cdots$ & $R_{144}$ \\
$F R_{2}$ & $R_{21}$ & $R_{22}$ & $\cdots$ & $R_{244}$ \\
$\cdots$ & $\cdots$ & $\cdots$ & $\cdots$ & $\cdots$ \\
$F R_{n}$ & $R_{n 1}$ & $R_{n 2}$ & $\cdots$ & $R_{n 44}$
\end{tabular}

Software FRs whose behaviors have been confirmed in the matrix are listed in 44 possible NFRs. $R_{i j}$ in the matrix is the evaluator's natural language evaluation on the correlation between the $i$ th FR and the $j$ th NFR.

\subsection{Calculation Process of the Fuzzy QFD}

\section{Expression of Natural Language Evaluation in Fuzzy Number}

Due to the complexity and uncertainty of software system development and the fuzziness of human thinking, FR-NFRS correlation can only be described with the fuzzy number rather than the specified one. Triangular fuzzy number and trapezoidal fuzzy number are widely used at present [37]. However, the shape of the membership function of triangular fuzzy number is so simple that it cannot reflect the decision information of 
the decision-makers well in many cases. In particular, when the decision is made based on certain factors, the evaluation result is often greatly different from the actual situation. The shape of the membership function of trapezoidal fuzzy number is more complicated, so it's able to deal with the actual decision-making information and reflect the uncertainty of factors.

Definition 1 If the trapezoidal membership function $\mu_{\tilde{q}}(X): R \rightarrow[0,1]$ meets:

$$
\mu_{\tilde{q}}(X)=\left\{\begin{array}{c}
\frac{x-a}{b-a}, X \in[a, b) ; \\
1, X \in[b, c) ; \\
\frac{d-X}{d-c}, X \in[c, d] ; \\
0, \text { other }
\end{array}\right.
$$

where $a, b, c, d \in R, a \leq b \leq c \leq d$, and $\tilde{q}=(a, b, c, d)$ is the standard trapezoidal fuzzy number.

In this paper, the FR-NFRS correlation evaluation is made with the 7-level natural language $\{\mathrm{C} 1, \mathrm{C} 2, \mathrm{C} 3, \mathrm{C} 4, \mathrm{C} 5, \mathrm{C} 6, \mathrm{C} 7\}$, and fuzzily processed with the standard trapezoidal fuzzy number. The trapezoidal fuzzy membership function under 7-level language evaluation is shown in Figure 3 . The interval $[0,1]$ is divided into 13 pieces, $(0.077,0.154,0.231, \ldots ., 0.846,0.923,1)$.

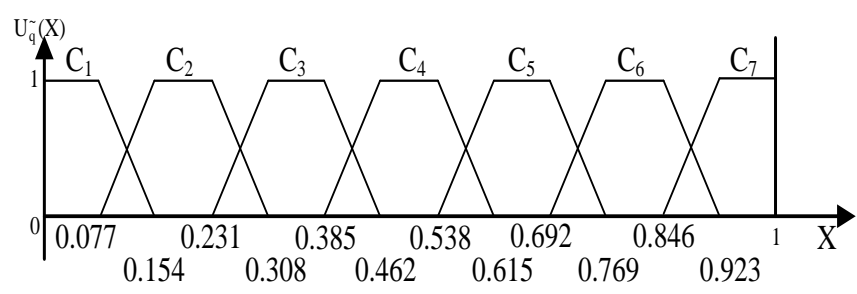

\section{Figure 3. Trapezoidal Fuzzy Membership Function of Level 7 Language Variable Set}

\section{Defuzzification of the Trapezoidal Fuzzy Number}

Since the direct calculation of the FR-NFR correlation matrix which is identified by the trapezoidal fuzzy number will cause the rapid expansion of the computing size and obstruct the practical application of this method (for example, for a $50 \times 44$ matrix, only three evaluators can produce 6600 evaluation data. If it's calculated with the trapezoidal fuzzy number directly, a most basic computation will have 26400 steps). Thus, the FRNFR matrix expressed by the trapezoidal fuzzy number is deffuzzified in the paper.

In the defuzzifying method, the gravity of the trapezoid can mostly represent the essential characteristics of the trapezoidal fuzzy number. It expresses the concentration place of the membership degree of the fuzzy numbers in the field. Therefore, the gravity of the fuzzy set can be used to describe the distribution of the membership functions. In other words, the gravity of the fuzzy set can represent the evaluation of experts.

Definition 2 If universe $\sigma$ is the bounded measurable value in the real number field, the gravity $G(A)$ of the trapezoidal fuzzy number A in $\sigma$ is:

$$
G(A)=\frac{\int_{W} \mu(x) \cdot x d x}{\int_{W} \mu(x) d x}
$$

The gravity of a trapezoidal fuzzy number $\mathrm{A}(\mathrm{a}, \mathrm{b}, \mathrm{c}, \mathrm{d})$ can be expressed as follows 
through the gravity calculation formula of trapezoid:

$$
G(A)=\frac{\left(d^{2}+c d+c^{2}\right)-\left(b^{2}+a b+a^{2}\right)}{3(d+c-b-a)}
$$

The defuzzified values of different levels of trapezoidal fuzzy numbers can be calculated by the above formula, as shown in Table 2 .

Table 2 The Defuzzified Values of Different Levels of Trapezoidal Fuzzy Numbers

\begin{tabular}{clc}
\hline Level & Trapezoidal Fuzzy Numbers & Defuzzified Values \\
\hline C1 & $(0,0,0.077,0.154)$ & 0.060 \\
C2 & $(0.077,0.154,0.231,0.308)$ & 0.193 \\
C3 & $(0.231,0.308,0.385,0.462)$ & 0.347 \\
C4 & $(0.385,0.462,0.538,0.615)$ & 0.500 \\
C5 & $(0.538,0.615,0.692,0.769)$ & 0.654 \\
C6 & $(0.692,0.769,0.846,0.923)$ & 0.808 \\
C7 & $(0.846,0.923,1,1)$ & 0.940 \\
\hline
\end{tabular}

\section{Calculation of Relative Importance and Absolute Importance}

Assuming there are $m$ relevant personnel evaluating the FRs of $\mathrm{n}$ systems, the importance evaluation given by the $k$ th evaluator is $W_{1}{ }^{k}, W_{2}{ }^{k} \ldots W_{n}{ }^{k}$ and the FR-NFR correlation matrix is $D^{k}=\left(R_{i j}^{k}\right)_{n \times 44}$, Then, the following can be obtained:

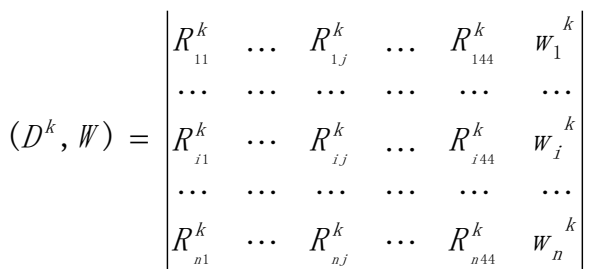

where $R_{i j}^{k}$ is the $F R_{i}-N F R_{j}$ correlation evaluation given by the $k$ th evaluator by the natural language; $w_{i}$ is the importance of $\mathrm{FR} 1, \mathrm{FR} 2, \ldots, \mathrm{FRn}$, expressed by the natural language. If $\bar{w}_{i}$ is set to be the average importance of $F R_{i}$ and $\bar{R}_{i j}$ is the average correlation between $F R_{i}$ and $N F R_{j}$, the following can be obtained:

$$
\bar{W}_{i}=\frac{1}{m} \sum_{k=1}^{m} G\left(\operatorname{fuzz}\left(W_{i}^{k}\right)\right), \quad \bar{R}_{i j}=\frac{1}{m} \sum_{k=1}^{m} G\left(\operatorname{fuzz}\left(R_{i j}^{k}\right)\right)
$$

Note: fuzzy in the formula is the trapezoidal fuzzy function of the natural language variable and $G$ is the gravity defuzzifying function.

Relative importance $A R_{j}$ and average relative importance $A A R$ of NFRs can be calculated through $\bar{w}_{i}$ and $\bar{R}_{i j}$.

$$
A R_{j}=\sum_{i=1}^{n} \bar{w}_{i} \cdot \bar{R}_{i j}
$$




$$
A A R=\frac{1}{n} \sum_{j=1}^{n} A R_{j}
$$

Absolute importance $R R$ of NFR can be got through the standardized treatment of $A R$. For example, the absolute importance $R R_{j}$ of the $j$ th NFRj is

$$
R R_{j}=\frac{A R_{j}}{\sum_{j=1}^{n} A R_{j}}
$$

\section{NFR Screening Algorithm}

If $R R_{j}$ of $N F R_{j}$ is equal to or greater than $A A R$, it means $N F R_{j}$ is necessary; in contrary, if $R R_{j}$ of $N F R_{j}$ is less than $A A R$, it means that the software system does not need this NFR. The screening algorithm is shown in Figure .4.

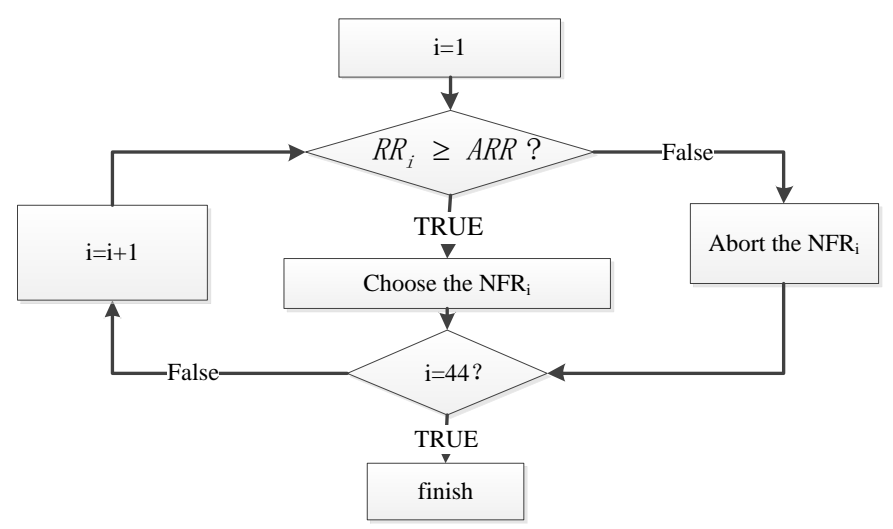

Figure 4. The Screening Algorithm

\subsection{Example Calculation}

Due to the limitation of space, this paper makes calculation with the correlation evaluation matrix which is composed of 20 NFRs in quality property and 10 FRs as examples, as shown in Table 3. ARs, RRs and ARRs of NFRs and the final screening results are shown in Table 4.

Due to the limitation of space, this paper makes calculation with the defuzzified correlation evaluation matrix which is composed of 20 NFRs in quality property and 10 FRs, as examples as shown in Table 3.

Table 3. Correlation Evaluation Matrix

\begin{tabular}{|l|l|l|l|l|l|l|l|l|l|l|}
\hline & FR1 & FR2 & FR3 & FR4 & FR5 & FR6 & FR7 & FR8 & FR9 & $\begin{array}{l}\text { FR1 } \\
\text { 0 }\end{array}$ \\
\hline Replaceability & 0.295 & 0.749 & 0.398 & 0.251 & 0.449 & 0.354 & 0.354 & 0.398 & 0.501 & 0.603 \\
\hline Installability & 0.896 & 0.647 & 0.302 & 0.749 & 0.295 & 0.347 & 0.456 & 0.456 & 0.200 & 0.544 \\
\hline Consistency & 0.500 & 0.705 & 0.896 & 0.551 & 0.596 & 0.647 & 0.398 & 0.845 & 0.500 & 0.705 \\
\hline Adaptability & 0.449 & 0.603 & 0.845 & 0.647 & 0.456 & 0.156 & 0.405 & 0.501 & 0.456 & 0.698 \\
\hline Testability & 0.251 & 0.302 & 0.244 & 0.398 & 0.500 & 0.500 & 0.302 & 0.507 & 0.603 & 0.347 \\
\hline Stability & 0.456 & 0.354 & 0.405 & 0.500 & 0.552 & 0.647 & 0.456 & 0.705 & 0.347 & 0.596 \\
\hline
\end{tabular}




\begin{tabular}{|l|l|l|l|l|l|l|l|l|l|l|}
\hline Changeability & 0.302 & 0.742 & 0.353 & 0.603 & 0.705 & 0.302 & 0.200 & 0.449 & 0.654 & 0.347 \\
\hline Analyzability & 0.200 & 0.200 & 0.302 & 0.603 & 0.654 & 0.398 & 0.354 & 0.405 & 0.251 & 0.793 \\
\hline Time Behaviour & 0.500 & 0.552 & 0.493 & 0.200 & 0.507 & 0.347 & 0.647 & 0.647 & 0.705 & 0.500 \\
\hline Resource Utilization & 0.698 & 0.501 & 0.200 & 0.500 & 0.552 & 0.501 & 0.603 & 0.156 & 0.354 & 0.295 \\
\hline Understandability & 0.449 & 0.757 & 0.845 & 0.456 & 0.295 & 0.398 & 0.603 & 0.654 & 0.104 & 0.507 \\
\hline Operability & 0.507 & 0.353 & 0.449 & 0.347 & 0.405 & 0.501 & 0.742 & 0.544 & 0.749 & 0.647 \\
\hline Recoverability & 0.449 & 0.603 & 0.251 & 0.647 & 0.647 & 0.808 & 0.500 & 0.296 & 0.552 & 0.398 \\
\hline Maturity & 0.698 & 0.354 & 0.647 & 0.852 & 0.347 & 0.302 & 0.493 & 0.500 & 0.309 & 0.449 \\
\hline Fault Tolerance & 0.258 & 0.500 & 0.449 & 0.449 & 0.296 & 0.698 & 0.251 & 0.654 & 0.551 & 0.354 \\
\hline Suitability & 0.442 & 0.552 & 0.603 & 0.302 & 0.500 & 0.501 & 0.654 & 0.603 & 0.302 & 0.545 \\
\hline Security & 0.200 & 0.302 & 0.596 & 0.449 & 0.193 & 0.405 & 0.501 & 0.354 & 0.493 & 0.801 \\
\hline interactivity & 0.354 & 0.691 & 0.852 & 0.551 & 0.449 & 0.449 & 0.347 & 0.251 & 0.500 & 0.940 \\
\hline Interoperability & 0.405 & 0.501 & 0.603 & 0.500 & 0.449 & 0.200 & 0.493 & 0.493 & 0.552 & 0.559 \\
\hline Accuracy & 0.603 & 0.742 & 0.353 & 0.200 & 0.442 & 0.251 & 0.493 & 0.405 & 0.696 & 0.493 \\
\hline
\end{tabular}

In addition, there are three part experts evaluating 10 FRs, the importance evaluation given by the $k$ th evaluator is $W_{1}{ }^{k}, W_{2}{ }^{k} W_{3}{ }^{k}$, which is expressed by 7-level natural language, as examples as shown in Table 4 . Then the importance evaluation of the 10FRs, it is weight, get the new vector by fuzzying and defuzzified number. After average three part experts, the weight of every FR become a set of vectors, as examples as shown in Table 5.

Table 4. The mportance Evaluation of the 10FRs

\begin{tabular}{|c|c|c|r|r|r|r|r|r|r|c|}
\hline & FR1 & FR2 & FR3 & FR4 & FR5 & FR6 & FR7 & FR8 & FR9 & FR10 \\
\hline experts $\mathrm{A}$ & $\mathrm{C}_{4}$ & $\mathrm{C}_{6}$ & $\mathrm{C}_{6}$ & $\mathrm{C}_{5}$ & $\mathrm{C}_{6}$ & $\mathrm{C}_{6}$ & $\mathrm{C}_{5}$ & $\mathrm{C}_{6}$ & $\mathrm{C}_{5}$ & $\mathrm{C}_{5}$ \\
\hline experts B & $\mathrm{C}_{5}$ & $\mathrm{C}_{6}$ & $\mathrm{C}_{6}$ & $\mathrm{C}_{5}$ & $\mathrm{C}_{6}$ & $\mathrm{C}_{6}$ & $\mathrm{C}_{5}$ & $\mathrm{C}_{4}$ & $\mathrm{C}_{4}$ & $\mathrm{C}_{4}$ \\
\hline experts $\mathrm{C}$ & $\mathrm{C}_{5}$ & $\mathrm{C}_{6}$ & $\mathrm{C}_{6}$ & $\mathrm{C}_{5}$ & $\mathrm{C}_{6}$ & $\mathrm{C}_{6}$ & $\mathrm{C}_{6}$ & $\mathrm{C}_{5}$ & $\mathrm{C}_{5}$ & $\mathrm{C}_{4}$ \\
\hline
\end{tabular}

Table 5 The Weight of the 10FRs

\begin{tabular}{|l|l|l|l|l|l|l|l|l|l|l|}
\hline & FR1 & FR2 & FR3 & FR4 & FR5 & FR6 & FR7 & FR8 & FR9 & FR10 \\
\hline weight & 0.603 & 0.808 & 0.808 & 0.654 & 0.808 & 0.808 & 0.705 & 0.654 & 0.603 & 0.551 \\
\hline
\end{tabular}

Calculate the vector of table 3 and table 5 by formula1-3, then ARs, RRs and ARRs of NFRs and the final screening results are shown in Table 6.

Table 6 AR and RR values of different NFRs

\begin{tabular}{|c|c|c|c|c|}
\hline \multicolumn{2}{|c|}{ NFR } & $A R$ & $R R^{*} 100$ & result \\
\hline \multirow{4}{*}{ Portability } & Replaceability & 3.06 & 4.51 & \\
\cline { 2 - 5 } & Installability & 3.36 & 4.94 & \\
\cline { 2 - 5 } & Consistency & 4.48 & 6.60 & $\sqrt{ }$ \\
\cline { 2 - 5 } & Adaptability & 3.63 & 5.34 & $\sqrt{ }$ \\
\hline
\end{tabular}




\begin{tabular}{|c|c|c|c|c|}
\hline \multirow{4}{*}{ Maintainability } & Testability & 2.76 & 4.06 & \\
\cline { 2 - 5 } & Stability & 3.50 & 5.16 & $\sqrt{ }$ \\
\cline { 2 - 5 } & Changeability & 3.30 & 4.85 & \\
\cline { 2 - 5 } Eerformance & Analyzability & 2.87 & 4.23 & \\
\hline \multirow{3}{*}{ Usability } & Time Behaviour & 3.55 & 5.22 & $\sqrt{ }$ \\
\cline { 2 - 5 } & Resource Utilization & 3.07 & 4.51 & \\
\hline \multirow{3}{*}{ Reliability } & Understandability & 3.62 & 5.32 & $\sqrt{ }$ \\
\cline { 2 - 5 } & Operability & 3.60 & 5.30 & $\sqrt{ }$ \\
\hline \multirow{5}{*}{ Functionality } & Recoverability & 3.66 & 5.38 & $\sqrt{ }$ \\
\cline { 2 - 5 } & Maturity & 3.42 & 5.03 & $\sqrt{ }$ \\
\cline { 2 - 5 } & Fault Tolerance & 3.15 & 4.64 & $\sqrt{ }$ \\
\cline { 2 - 5 } & Suitability & 3.54 & 5.21 & $\sqrt{ }$ \\
\cline { 2 - 5 } & Security & 2.95 & 4.34 & \\
\cline { 2 - 5 } & interactivity & 3.77 & 5.55 & \\
\cline { 2 - 5 } & Interoperability & 3.30 & 4.85 & \\
\cline { 2 - 5 } & Accuracy & 3.36 & 4.95 & \\
\hline \multicolumn{2}{|c|}{$A R R$} & 5.00 & \\
\hline
\end{tabular}

\section{Conclusion}

This paper set up the model which express correlation evaluation with the 7-level natural language, build software FR-NFR correlation matrix, fuzzy the matrix vector by the trapezoidal fuzzy number, then calculate the relative importance and absolute importance of NFR, at last get the importance NFR by the NFR screening algorithm.In addition,this paper generalizes 44 NFRs based on the literature research and puts forward a systemized software NFR determination based on the fuzzy-QFD process according to the correlation and interdependence between FR and NFR of software, which provides a new solution for the identification of NFR in the real software program.

\section{References}

[1] J. Karlsson . "Managing software requirements using quality function deployment". Software Quality Journal, 6, (1997), pp. 311-325.

[2] N. Maiden, "Requirements Critiquing Using Domain Abstractions", Los Alamitos, CA: IEEE Computer Society Press, (1994), pp.184-193.

[3] R Q Jin Z,Lu, “ Automatic Multi-paradigm Requirements Modeling and Analysis:an Approach Based on Ontology", Science in China(Series E), 04,( 2003) , pp.297-312.

[4] N. Howes, "On Using the Users Manual as the Requirements Specification" Los Alamitos CA: IEEE Computer Society Press, (1990), pp.164-169.

[5] I. Sommerville, Software Engineering, Boston: Addison-Wesley,(2006).

[6] A. Anton, Potts C. "A representational framework for scenarios of system use"[J]. Requirements Engineering Journal, 3, (1998), pp..219-241.

[7] K .Breitman, J Leite, Berry D. Supporting scenario evolution. Requirements Engineering, 10, (2005), pp.112-131.

[8] E. Hull, K. Jackson ,J. Dick . Requirements Engineering. Springer, (2005).

[9] M. Kans, "An approach for determining the requirements of computerized maintenance management systems",Computers in Industry, vol.59, no.3, (2008), pp. 32-40.

[10] V. Nilsson, B. Fagerstro, "Managing stakeholder requirements in a product modeling system". Computers in Industry, vol.57, no.2, (2006), pp.167-177.

[11] H. Shen , B. Wall , M. Zaremba, "Integration of business modeling methods for enterprise information system analysis and user requirements gathering", Computers in Industry, vol.54, no.4, (2004), pp.307323.

[12] R. Machado, Borges M, Guerlain S, Gomes J. An Observation Model for the Collaborative Analysis of Real Workplaces[C]. Melbourne Australia:Proceedings of the International Conference on Computer Supported Cooperative Work in Design, (2007), pp. 292-297. 
[13] P. Antunes , J. Ramirez, A. Respicio , "Addressing the conflicting dimension of groupware: a case study in software requirements validation", Computing and Informatics, vol.25, no.5, (2006), pp.523546.

[14] C. Hofmeister, P. Kruchten, Nord R L,Obbink H,Ran A,America P. "A general model of software architecture design derived from five industrial approaches", The Journal of Systems and Software, 80,(2007), pp.106-126.

[15] I. Errol, Ferrell W G, “A methodology for selection problems with multiple, conflicting objective and both qualitative and quantitative criteria", International Journal of Production Economics, 86, (2003), pp.187-199.

[16] Illa X B, Franch X, Pastor J A, "Formalising ERP selection criteria. In Proceedings of the 10th international workshop on software specification and design", Shelter Island, San Diego, California,(2000), pp. 115-123.

[17] Kunda L, BrooksD.Applying social-technical approach for COTS selection. In 4th UKAIS conference proceedings: Information systems-The next generation,University of New York, (1999), pp.552-565.

[18] M. A.Ochs, Pfahl D, ChrobokG, Nothhelfer-Kolb B. A COTS acquisition process: Definition and application experience.In Proceedings of the 11th ESCOM conference Shaker, Maastricht, (2000), pp. 335-343.

[19] Wei C C, Wang M J. A comprehensive framework for selecting an ERP system. International Journal of Project Management, 22, (2004) , pp.161-169.

[20] Wei C C, Chien C, Wang M J.An AHP-based approach to ERP system selection. International Journal of Production Economics, 96, (2005), pp.47-62.

[21] B. Baki,cakar K. "Determining the ERP package-selecting criteria: The case of Turkish manufacturing companies [J]", Business Process Management Journal, 11(1), (2005) , pp.75-86.

[22] M. Keil , Tiwana A. "Relative importance of evaluation criteria for enterprise systems: A conjoint study[J]", Information Systems Journal, 16, (2006) , pp.237-262.

[23] J. Kontio ,Chen S,Limperos K,Tesoriero R, Caldiera G,DeutschM.A COTS selection method and experiences of its use. In Twentieth annual software engineering workshop, Greenbelt, Maryland, USA, (1995), pp.189-215.

[24] C. N. Maiden, Ncube A M. "PORE: Procurement-oriented requirements engineering method for the component-based systems engineering development paradigm", In 2nd international workshop on component-based software engineering, Los Angeles, USA, (1999), pp.1-12.

[25] P. Kruchten, "The rational unified process: An introduction", Boston: Addison-Wesley, (2003).

[26] X F Liu, "A quantitative approach for assessing the priorities of software quality requirements. The Journal of Systems and Software, 42, (1998), pp.105-113

[27] W D Barnett, M K Raja, "Application of QFD to the software development process", International Journal of Quality and Reliability Management, 12(6), (1995), pp.22-42.

[28] S. Bot ,Lung C H, Farrell M. A stakeholder-centric software architectureanalysis approach. In Proceedings of the second international software architecture workshop (ISAW-2), San Francisco, California, USA, (1996), pp.152-154.

[29] J C Duenas,DeOliveira W L, De La Puente JA. "A software architecture evaluation model”, In Proceedings of the Second International ESPIRIT ARES Workshop, LNCS, Las Palmas, (1998), pp.148-157.

[30] G . Buyukozkan, Feyziog lu O. (). Group decision making to better respond customer needs in software development[J]. Computers and Industrial Engineering, 48, (2005), pp.427-441.

[31] S. Herzwurm , G.Schockert, "The leading edge in OFD for software and electronic business",[J] The International Journal of Quality and Reliability Management, 20(1), (2003), pp.36-55.

[32] Liu X F. "Software quality function deployment[J]", IEEE Potentials, 19(5), (2001), pp.14-16.

[33] R. J,AntunesP, Respício A, "Software requirements negotiation using the software quality function deployment", Lecture Notes in Computer Science, (2005), pp.308-324.

[34] ISO/IEC-Standards-9126. "International Standards Organisation.Information technology software product evaluationquality characteristics and guidelines for their use", (1991).

[35] L. Kunda , D. Brooks. “Applying social-technical approach for COTS selection”[J]. In 4th UKAIS conference proceedings: Information systems-The next generation, University of New York, (1999), pp.552-565.

[36] L. Vanegas V, A W Labib. "A fuzzy quality function deployment (FQFD) model for deriving optimum targets", International Journal of Production Research, 1(39), (2001), pp.99-120.

[37] S-C Xiao, J-F Wu, H. He, Z-Do Yang, X. Shen. "An emergency logistics transportation path optimization model by using trap" ezoidal fuzzy, 11th International Conference on Fuzzy Systems and Knowledge Discovery, (2014), pp.199-203. 


\section{Authors}

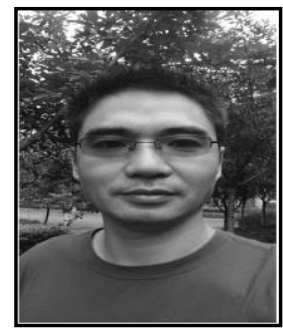

Shucheng Xiao, he received his BS degree from Lanzhou University, in 1998 and his MS degree from Chongqing University, China, in 2003. He is currently anassociate professor in Logistic Engineering University, China. His current research interests include IOT and computer system. Email: xiaosc@cqu.edu.cn 